\section{Acquisition of free-operant (Sidman) avoidance in Mongolian gerbils}

\section{(Meriones unguiculatus) and albino rats*}

\author{
ROBERT W. POWELL \\ University of South Florida, Tampa, Fla. 33620
}

Mongolian gerbils were generally superior to albino rats in the acquisition of free-operant avoidance. Members of both species learned to avoid much more successfully when the shock-shock interval was of shorter duration than the response-shock interval, as compared to acquisition when these intervals were equal. As a whole, the results extend the generality of data obtained from albino rats in avoidance situations.

The behavior of the Mongolian gerbil has been studied with increasing frequency in recent years. Gerbils have been tested in a variety of situations including mazes (Wise \& Parker, 1968), shuttleboxes (Boice, Boice, \& Dunham, 1968), operant-conditioning chambers (Powell \& Peck, 1969; Campbell, Straney, \& Neuringer, 1969), a miniaturized WGTA (Blass \& Rollin, 1969), and a passive-avoidance task (Lippman, Galosy, \& Thompson, 1970). For the most part, gerbils have performed effectively in these problems, but interspecies comparisons have been limited by the small number of $S$ employed or the short-term nature of the study.

Perhaps an even greater impediment to meaningful species comparisons has been the failure to determine parameter values of variables which are functionally equivalent for the different species under study. For example, Campbell et al studied operant responding in gerbils under several reinforcement schedules, with chocolate milk as the reinforcer. The animals learned to respond, but response patterns were generally erratic. The authors point out that their results might indicate (1) that the reinforcer was relatively weak, (2) that the level of deprivation was not very great, or (3) that food per se might be a relatively weak reinforcer for the gerbil. In order to compare different species in the same task, researchers must first demonstrate that the reinforcers employed have equivalent incentive value for the different animals under study.

The present experiment was undertaken to compare avoidance learning in gerbils and albino rats. Shock parameters were employed which had produced optimal avoidance responding in each species in an earlier study in this laboratory (Powell \& Peck, 1969).

* Reprints may be obtained from the author. Department of Behavioral Science, University of South Florida, Tampa, Fla. 33620 .

\section{SUBJECTS}

Twenty-seven adult experimentally naive Mongolian gerbils (Meriones unguiculatus), 15 male and 12 female, and 32 adult experimentally naive albino rats (Sprague-Dawley derived), 16 male and 16 female, were used. All Ss were 120-180 days old at the beginning of the experiment and had free access to water and Purina Lab Chow in their home cages at all times. The weight range for each group was $80-130 \mathrm{~g}$ for the gerbils and $150-275 \mathrm{~g}$ for the rats.

Both rats and gerbils are members of the order Rodentia and the suborder Myomorpha. Gerbils belong to the family Cricetidae. It is generally believed that domestic rat strains were all developed from Rattus norwegicus stock (Barnett, 1963), and this species belongs to the family Muridae.

\section{APPARATUS}

All animals were studied in a Lehigh Valley small-animal test chamber, Model $1316,73 / 4 \times 8 \times 9$ in. $(197 \times 203 \times 229 \mathrm{~mm})$, with a single lever at the right side of one end, $1-3 / 8$ in. $(35 \mathrm{~mm}$ ) from the grid floor. Electric shock was provided by a Lehigh Valley constant-current shock source, Model 1531, and was scrambled to the grid floor of the test chamber. Data were recorded by digital counters and a Gerbrands cumulative recorder.

\section{PROCEDURE}

A free-operant avoidance procedure (Sidman, 1953) was used with all Ss. Under this procedure, a fixed time interval occurs between the presentation of brief electric shocks in the absence of a leverpress response (shock-shock interval), and each response postpones the next shock for a fixed period of time (response-shock interval). The animals were divided into four groups per species, according to the following avoidance parameters: (1) shock-shock interval $=5 \mathrm{sec}$, response-shock interval $=20 \mathrm{sec}$, eight rats, eight gerbils; (2) shock-shock interval $=10 \mathrm{sec}$, response-shock interval $=20 \mathrm{sec}$, eight rats, seven gerbils; (3) shock-shock interval = $10 \mathrm{sec}$, response-shock interval = $10 \mathrm{sec}$, eight rats, seven gerbils; (4) shock-shock interval $=20 \mathrm{sec}$, response-shock interval $=20 \mathrm{sec}$, eight rats, seven gerbils.

The shock duration was $0.5 \mathrm{sec}$. Shock intensity was $1.50 \mathrm{~mA}$. Responses in the presence of shock did not terminate it. Experimental sessions were $1 \mathrm{~h} /$ day for each animal.

Gerbils appear to be somewhat less sensitive to footshock than are albino rats because they have a greater density of hair on the feet. This factor was compensated for through the use of a shock intensity which was relatively more aversive to the gerbils because of their smaller size. The a versivity of a particular shock intensity is generally assumed to increase as body size decreases, since decreases in resistance are correlated with decreases in body size, other things being equal. In any case, the shock intensity employed had already been shown to produce optimal avoidance in both species under study (Powell \& Peck, 1969).

The criterion for learning was a reduction in the mean number of shocks over 10 consecutive sessions to $20 \%$ less than would occur in the absence of any responses. All animals were studied until one of the following conditions was achieved: (1) The animal learned to avoid and the number of shocks received had a range of 20 or less over 10 consecutive sessions, i.e., the largest number of shocks in any of the 10 sessions could not exceed the fewest shocks by more than $20 ;(2)$ the animal failed to learn and 20 sessions were completed; or (3) the animal learned, but performance was unstable, and 30 sessions were completed.

\section{RESULTS AND DISCUSSION}

The mean performance for each animal over the final 10 sessions is presented in Table 1. Animals of both species learned to avoid much more successfully when the shock-shock interval was shorter than the response-shock interval. All of the animals in Conditions 1 and 2, except Gerbil 29F, attained the avoidance criterion. A Kruskal-Wallis analysis of variance was performed which compared the mean shock rates over the final 10 sessions for the animals studied under these conditions. Even though one gerbil failed to learn, the terminal performance for this group was superior to that for the rats $(\mathrm{H}=3.84, \mathrm{df}=1, \mathrm{p}<.05)$.

Only a minority of animals from each species learned to avoid when the shock-shock and response-shock intervals were equal. Kruskal-Wallis analyses which compared terminal 
shock rates revealed no difference between species under Condition 3 $(\mathrm{H}=.85, \mathrm{df}=1, \mathrm{p}<.50)$, but the performance of the gerbils was again superior under Condition $4(\mathrm{H}=4.85$, $\mathrm{df}=1, \mathrm{p}<.05$ ). Because of the large number of animals that failed to learn under these conditions and the resulting inequality in shock rates between the two conditions, it did not seem appropriate to combine the data across these two conditions.

The value of results obtained from domesticated rats in behavioral experiments has been questioned periodically (Beach, 1950; Richter, 1959; Kavanau, 1967; Lockard, 1968). Specifically, the contention has been that domesticated animals are products of an unnatural environment, in which the normal contingencies of survival do not obtain. Therefore, experimental results obtained from such animals may lack generality to species which are products of a natural environment. The relative state of domestication of the Mongolian gerbil is an open question, gerbils having been bred for research purposes in this country since 1952 (Monroe, 1967). The domestication of rats seems to have progressed much further, however, with most laboratory colonies dating back to the beginning of this century (Barnett, 1963).

Although the present results show that Mongolian gerbils are generally superior to albino rats in the acquisition of free-operant avoidance, both species learned to avoid much more successfully when the shock-shock interval was of shorter duration than the response-shock interval, as compared to acquisition when these intervals were equal. This finding suggests that the same basic learning principles were operating in each species and thus extends the generality of data obtained from domesticated rats to a semidomesticated rodent species.
The more successful avoidance of the gerbils may relate to the higher rates of leverpressing which these animals display when there is no contingency present (Powell \& Peck, 1969).

The successful performance of the gerbils studied here, plus their docility and ease of maintenance, further recommends members of this species as Ss for laboratory research.

\section{REFERENCES}

BARNETT, S. A., The rat. Chicago: Aldine, 1963.

$\mathrm{BEACH}$, F. A. The snark was a boojum. American Psychologist, 1950, 5, 115-124.

BLASS, E. M. \& ROLLIN, R. A. Formation of object discrimination learning sets by Mongolian gerbils. Journal of Comparative \& Physiological Psychology, 1969, 69, 519-521.

BOICE, R., BOICE, C., \& DUNHAM, A. E. Role of docility in a shuttlebox. Psychonomic Science, 1968, 1y, 371-372. CAMPBELL, N., STRANEY, D., \& NEURINGER, A. Operant conditioning in the Mongolian gerbil. Psychonomic Science, 1969, 16, 255-256.

Table 1

Mean Performance for Each Animal Under Each of the Experimental Conditions Over the Final 10 Sessions

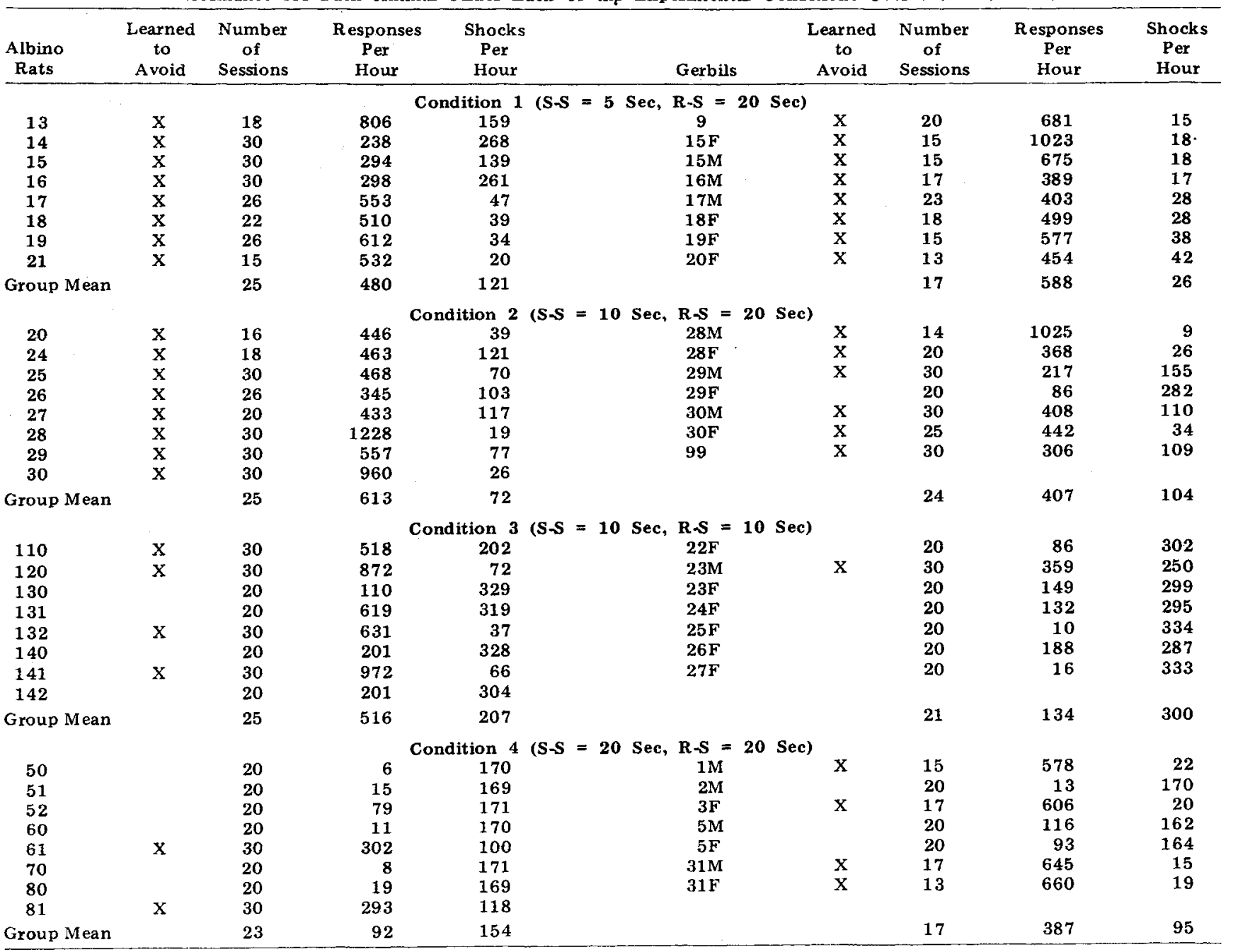


KAVANAU, L. Behavior of captive white footed mice. Science, 1967, 155, 1623-1629.

LIPPMAN, L. G. GALOSY, R. A., \& THOMPSON, $\ddot{R}$. W. Passive-avoidance learning in gerbils and rats. Journal of Comparative \& Physiological Psychology, $1970,73,269-273$

LOCKARD, R. B. The albino rat: A defensible choice or a bad habit? American Psychologist, 1968, 23, 734-742.

MONROE, B. N. Gerbils. Jersey City, N.J: T.F.H. Publications, 1967.
POWELL. R. W., \& PECK, S. Activity and avoidance in the Mongolian gerbil. Journal of the Experimental Analysis of Behavior, 1969, 12,779-787.

RICHTER, C. P. Rats, man, and the welfare state. American Psychologist, 1959, 14. 18-28.

SIDMAN, M. Two temporal parameters of the maintenance of avoidance behavior by the white rat. Journal of Comparative \& Physiological Psychology, 1953, 46. 253-261.

WISE, L. M., \& PARKER, E. Discriminative maze learning in the Mongolian gerbil. Psychological Record, 1968, 18, 201-204.

\title{
Spatial reversal learning in rats, pigeons, and goldfish*
}

\author{
N. J. MACKINTOSH, Dalhousie University, Halifax, N.S., Canada \\ and \\ ANN CAUTY, Mount Allison University, Sackville, N.B., Canada
}

Four rats, four pigeons, and four goldfish were trained under comparable conditions for 40 trials per day on a spatial discrimination and a series of 30 daily reversals. All three groups of animals showed a significant reduction in errors per reversal over the course of the experiment, but the rats improved much more rapidly than the pigeons, who in turn improved more rapidly than the goldfish.

Although a number of investigators have recently observed substantial differences in the performance of different animal groups trained on serial reversal tasks (e.g., Bitterman, 1965; Gossette, 1966; Mackintosh, 1969 ), several questions of interpretation remain. One problem is to know if any particular difference observed between, say, the performance of goldfish and rats reflects anything more than differences in the experimental condition under which the two groups were studied. A second question is whether or not differences in performance should be described as qualitative or quantitative. Bitterman (1965), for example, has argued that since fish typically show no improvement in performance over a series of reversals, there must be qualitative differences in mechani ms of learning (or retention) betwein them and rats. The complete absence of improvement in fish, however, may be due to less than optimal experimental conditions; one obvious respect in which the apparatus used for fish has usually differed from that

\footnotetext{
* This research was supported by Grant APA-259 from the National Research Council of Canada.
}

used for rats or pigeons has been in the contiguity between stimulus, response, and reinforcement. Fish have usually been reinforced by food dropped onto the surface of the water-often near the back of their tank. Rats and pigeons usually receive reinforcement from a magazine located close to the response keys. When we trained some rats on a series of spatial reversals under conditions similar to those reported in the present study-with the exception that the food magazine was located on the back wall of the box, we found that, although still showing highly significant improvement, they averaged nearly twice as many errors per reversal as the rats in the present study. It therefore seemed desirable to study the reversal performance of fish under more favorable conditions. In this experiment, we used a reinforcement device described by Ames (1967), which delivered paste food to a magazine located midway between the two response keys.

\section{METHOD}

The Ss were four male hooded rats, approximately 4 months old, four White Carneaux pigeons, approximately 6 months old, and four 5-in. goldfish. Motivation was maintained by feeding sufficient food after each day's trials to maintain the rats at $85 \%$ and the pigeons at $80 \%$ of their ad lib weights; the goldfish were fed a pinch of Tetramin staple food each day.

The apparatus used for the rats was a $9 \times 9 \times 9$ in. box housed in a sound-insulated shell. One wall of the box contained two 1-in.-diam response keys mounted $2^{1 / 2}$ in. from the floor and $4 \mathrm{in.}$ apart, with a magazine opening midway between them. Correct responses were reinforced with one 45-mg Noyes pellet and the illumination of a light in the magazine opening for $3 \mathrm{sec}$. The pigeons were trained in a standard two-key box, also with a central magazine opening. Reinforcement consisted of $3 \mathrm{sec}$ access to grain during which the magazine was illuminated. The fish were trained in their living tanks. A black Plexiglas box was fitted tightly over the tank and contained a black Plexiglas screen which covered one end wall of the tank. The screen contained two 1-in.-diam holes 3 in. from the bottom and 2 in. apart. Behind the holes were mounted paddles which, when touched, activated two phonograph cartridges whose outputs were amplified to operate relays. Midway between the two paddles was the opening of the magazine. Reinforcement was delivered by raising the shutter that covered the opening of the magazine and turning on a light for 5 sec. Food (Tetramin tube food) was delivered to the magazine opening via a 14-ga polyethylene tube attached to a hypodermic syringe mounted on the top of the box. For each reinforcement, a motor was operated for 2 sec to drive the syringe.

The training procedure was identical for all Ss. After being pretrained to eat from the magazine and being reinforced for responding to whichever response key was illuminated from behind with a white light, all Ss received 40 noncorrection trials daily for 31 days. A trial started with the illumination of the two response keys with white light. A response on either key turned both lights off, and, if correct, led to reinforcement. After reinforcement (or immediately after an incorrect response) there was a 25-sec intertrial interval spent in darkness. All Ss were initially trained with the left key correct, and were thereafter reversed every day for a total of 30 reversals. All experimental events were programmed and recorded automatically.

\section{RESULTS}

Figure 1 shows the mean number of errors per problem for original learning and each of 30 reversals. It is clear that the rats were very much more efficient than either the pigeons or the goldfish, 